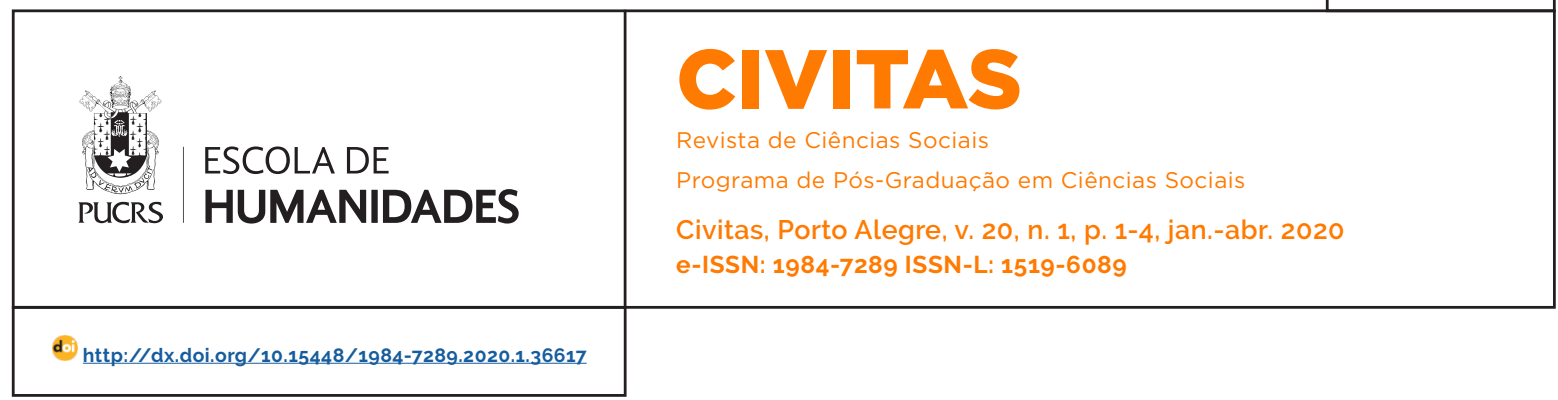

APRESENTAÇÃO

\title{
Os novos desafios do desenvolvimento na região amazônica
}

New development challenges in the Amazonian region

\section{Nuevos desafíos de desarrollo en la región amazónica}

\section{Márcia Grisotti ${ }^{1}$}

orcid.org/0000-0003-0389-7100

grisotti@fastlane.com.br

\section{Emilio Federico Moran² \\ orcid.org/0000-0001-5153-545X moranef@msu.edu}

Recebido em: 8 dez. 2019 Aprovado em: 8 dez. 2019 Publicado em: 25 mai. 2020

\section{(c) (1)}

Artigo está licenciado sob forma de uma licença Creative Commons Atribuição 4.0 Internacional.
Falar do desenvolvimento da região amazônica nos leva, desde já, por um caminho errado. Não existe uma região amazônica, mas muitas Amazônias, cada uma com características únicas e que precisam de estratégias de desenvolvimento únicas também. A região do Rio Negro nem parece como o restante da Amazônia, com suas árvores tortas e vegetação de campina. A várzea, ao longo do rio Amazonas, com sua fertilidade renovada pelos sedimentos andinos. A área de transição entre floresta úmida e o cerrado em Mato Grosso, que forma parte da Amazônia Legal, com sua mistura de savana, árvores e solos roxos, hoje sendo transformada em campos de soja. As matas de cipó do Xingu com alta fertilidade e potencial para agricultura intensiva, ocupadas por pastagens. Poderíamos continuar os exemplos por muitas páginas.

Um dos aspectos que mais atrasa o desenvolvimento das Amazônias é a persistente ignorância dessa diversidade geológica, ecológica e humana. O reconhecimento da diversidade, que deveria ser o ponto de partida para qualquer discussão sobre estratégias de desenvolvimento na região, é negligenciado pelas políticas públicas, que continuam procurando soluções para a região como se ela fosse homogênea. Essa constatação não é totalmente nova. Ao longo do tempo, pesquisas têm evidenciado a riqueza do Rio Negro, especialmente quanto aos componentes químicos das plantas da região que poderiam ser utilizadas pela farmacologia. O grande etnobotânico da Universidade de Harvard, Richard Schultes (1979, 1990), já escrevia sobre isso desde os anos 1950, durante as suas viagens de campo; e muitas outras expedições foram realizadas à procura de curas para muitas doenças. Por que as indústrias que potencializam a biodiversidade para fins medicinais não têm florescido na região? Provavelmente, a falta de apoio em termos de infraestrutura para cientistas poderem lá trabalhar a longo prazo. O Rio Negro sofre mais do que outras áreas esse isolamento comum para muitas áreas da Amazônia. A várzea, com sua riqueza sedimentar renovada anualmente, poderia alimentar grande parte do País, no entanto, 
a agricultura continua de forma elementar e sem inovações tecnológicas nessa região. A pesca e o transporte fluvial não têm avançado em um século. As perdas de mercadorias continuam altas para os comerciantes, que acabam elevando os preços dos produtos para cobrir as suas perdas. $O$ investimento no transporte fluvial é um vexame, e ninguém parece responsabilizado por isso. A única área que mostra alguma inovação tem sido o cerrado, onde a soja mecanizada tem se expandido nas últimas três décadas e enriquecido cada vez mais os seus produtores. No entanto, essa expansão tem ocorrido de forma mal controlada, com muitas áreas desmatadas acima do permitido pelo Código Florestal Brasileiro e sem punição pela ilegalidade.

Esse contexto nos leva ao tema dos vários trabalhos apresentados neste dossiê: a explosão no desenvolvimento da hidroenergia na Amazônia. Desde Tucurui, nos finais dos anos 1970, até Samuel e Balbina nos anos 1980 (Fearnside 2005), entre outras, o setor energético têm visto a Amazônia como a nova fronteira do desenvolvimento energético do País. De fato, a região possui mais da metade desse potencial (como tem mais da metade do território do País). especialmente no Xingu, Tapajós e Madeira, nos quais existe potencial e grandes planos para seu desenvolvimento nos próximos anos.

Esse processo já iniciou: em 2008, no Rio Madeira, com a construção de Santo Antonio e Jirau (completadas em 2012 e 2013), em 2011. com Belo Monte (completada a instalação das últimas turbinas no ano de 2019). Teriamos outras em construção no Tapajós, evitadas pela ação jurídica dos indigenas Munduruku que paralisou as obras devido à violação de seus direitos, garantidos pela constituição de 1988 . Ainda assim, sete hidrelétricas foram planejadas e ainda podem ser construidas; cogita-se a construção de outras no Xingu porque Belo Monte não está gerando a energia prevista Por incrivel que pareça, representantes da Norte Energia (consórcio construtor liderado pela Eletronorte) ficam surpresos quando as áreas alagadas pelas usinas acabam sendo maiores do que previsto (aumentando a destruição das florestas), quando o potencial instalado não chega nem a metade do previsto por não ter considerado as flutuações sazonais dos rios da Amazônia (fato óbvio nos dados da Agência Nacional de Águas, disponíveis a todos no País). Ou ainda, quando as grandes secas que ocorrem em toda a região Norte, em anos do fenômeno climático de El Niño, produzem situações em que a quantidade de água se torna insuficiente para uma produção adequada de hidroenergia. Esses fatores deveriam ter impedido a construção de muitas hidrelétricas, no entanto, os projetos receberam autorização, mesmo quando os estudos de impacto ambiental e social demandavam modificações estruturais nos planos de construção para reduzirem os impactos sociais e ambientais.

As barragens hidrelétricas detêm um importante significado como um dos principais projetos de desenvolvimento de grande escala que trazem influxo de gente e capital repentino no contexto de economias menos desenvolvidas. Esses eventos episódicos e de grande magnitude afetam a curto e longo prazo as trajetórias de uma região de formas ainda muito pouco entendidas. O processo de planejamento pode levar muitos anos (23 anos no caso de Belo Monte), envolver múltiplos reajustes ao projeto original em resposta a pressões políticas e interesses locais e nacionais (incluindo, nesse caso, mudanças na localização da barragem e do reservatório), provocar impactos durante os vários anos de duração da construção e o contínuo impacto às pessoas e ambiente por décadas, depois do fim da construção. Por essas razões, estudos prospectivos desses contextos são raros ou incompletos. O forte compromisso brasileiro relativo à geração de energia hidrelétrica torna urgente a produção de análises e recomendações de credibilidade visando reduzir resultados negativos ao meio-ambiente, saúde, sociedade e economia (Moran 2016).

O processo de desenvolvimento energético, que deveria representar uma abertura de oportunidades para a região amazônica e seus diversos habitantes, acabou sendo um desastre 
ecológico e humano. As hidrelétricas, até agora, têm sido construidas visando produzir energia para o país (principalmente para as regiões costeiras e urbano-industriais) sem pensar nas necessidades energéticas da região amazônica. As linhas de transmissão escoam a energia e deixam pouca nas Amazônias; o que deixam são rios empobrecidos de peixe, pescadores arruinados, populações urbanas, rurais, ribeirinhas e indigenas afetadas e com injusta compensação pelos danos sociais, econômicos e ambientais. As populações a jusante do barramento, não têm sido nem consultadas, nem compensadas apesar de sentirem as maiores perdas e impactos negativos.

O dossiê Os novos desafios do desenvolvimento na região amazônica, aborda as interações entre ambiente e sociedade e, em particular, sobre o impacto de projetos em infraestruturas de grande escala sobre as comunidades atingidas, e pretende contribuir, através de análises ambientais e sóciodemográficas, no reordenamento das políticas públicas e de desenvolvimento. Os autores são pesquisadores com um histórico de pesquisas sobre os impactos de grandes empreendimentos em diversas regiões da Amazônia, com maior destaque para a hidrelétrica de Belo Monte. a terceira maior do mundo. Os trabalhos apresentados incluem análises que colocam o debate em perspectiva histórica, mostrando que os grandes projetos de construção levam a grandes efeitos colaterais que nem sempre são levados em consideração quando foram planejados e construidos. Essa falta de perspectiva histórica (deliberada ou não) em aprender com os erros do passado conduz às repetições dos erros e à criação de programas emergenciais para sanálos, resultando em superposições de programas institucionais, ausência de coordenação, controle e avaliação, reduzindo, com isso, a eficácia das políticas socais e ambientais e do processo de desenvolvimento do país.

O dossiê começa com o artigo de Emilio Moran, no qual procura colocar em contexto o porquê do desenvolvimento da hidroenergia, a realidade de como tem ocorrido, desrespeitando as pessoas da região, prometendo e não cumprindo com as obrigações para melhorar o abastecimento de água e saneamento (requeridos pela legislação brasileira), de compensar aos atingidos pelas barragens de forma justa, e de consultar e modificar as obras em função do que elas requerem. O autor detalha as falhas do processo de planejamento, execução e mitigação dos danos socioambientais causados pela construção de hidrelétricas, apontando sugestões para futuros projetos de grandes obras de infraestrutura.

O artigo de Vanessa Boanada Fuchs analisa a crescente demanda externa de soja, especialmente da China, e as pressões causadas pela expansão das fronteiras de soja - de uma área consolidada no Mato Grosso para outros municípios que estão na fronteira do arco de desmatamento da Amazônia - apontando uma possivel correlação entre a expansão das plantações sobre as pastagens, a disponibilidade de infraestrutura logística e o desmatamento da floresta tropical. A autora chama atenção para necessidade de antecipação das consequências (para o meio ambiente, o clima e a manutenção de modos de vida específicos) da expansão da soja nos territórios da Amazônia, apresentando uma agenda de questões para futuras pesquisas e para formulação de políticas públicas.

O artigo de Marcia Grisotti, Marina Reche Felipe e André Ramos analisa o processo de aceitabilidade social da Usina Hidrelétrica de Belo Monte e as disputas em torno da responsabilização pelos impactos à saúde, através da análise da Câmara Técnica de Saúde do Plano de Desenvolvimento Regional Sustentável do Xingu. A análise sobre a gestão desse Plano evidenciou como as relações imprecisas e conflituosas entre os setores públicos e privados afetaram as atribuições de responsabilidades em relação aos impactos socioambientais. Os autores problematizam as assimetrias de poder entre os grupos sociais e as agências de governo (e dentro delas), as relações público-privado, as fragilidades do pacto federativo brasileiro e a tendência para a sobreposição de esforços em participação social, sem articulação com os mecanismos de participação e controle sociais já existentes, reduzindo a eficácia do 
Plano em garantir a sustentabilidade do território impactado por Belo Monte.

O artigo de Maira Borges Fainguelernt analisa os impactos da Usina Hidrelétrica de Belo Monte. percebidos pelas populações ribeirinhas, mais especificamente os moradores das Reservas Extrativistas (Resexs) da Terra do Meio, os quais foram excluidos dos estudos prévios de impactos socioambientais da Usina de Belo Monte. Através do clássico trabalho de Vainer (2003), a autora analisa o conceito de atingido, demonstrando que a territorialidade ribeirinha e as especificidades de seus modos de vida (intimamente ligadas ao rio, à floresta e à cidade) foram subdimensionadas no contexto de estudo dos impactos de Belo Monte. fato que dificulta a visibilidade das populações ribeirinhas e a adoção de medidas de mitigação, compensação e políticas públicas mais coerentes com a realidade destas populações.

O artigo de Assis da Costa Oliveira analisa como a implantação de grandes empreendimentos econômicos na região do Tapajós, especialmente na cidade de Itaituba, Pará, tem afetado os direitos de crianças e adolescentes, especialmente os impactos relacionados à violência sexual, convivência familiar e comunitária. O autor realiza um diagnóstico da dinâmica de produção destas violações de direitos e suas relações com as atividades econômicas e propõe medidas de responsabilização do Estado e das empresas.

Os autores reconhecem a importância de estradas, do setor elétrico e, essencialmente, da produção de energia para o desenvolvimento do País. O que lhes parece problemático é a repetição de erros do passado e a frequência com que se ignora os requerimentos da lei, da Constituição, e dos direitos das populações locais na construção destas grandes obras de infraestrutura. Os artigos tratam de aspectos específicos dessa problemática, articulados com análises que sugerem modificações sobre como é possivel combinar a necessidade de desenvolvimento nacional, sem ignorar os direitos, a dignidade e os valores das populações diretamente e indiretamente afetadas pelo processo de construção de grandes projetos na região amazônica.

\section{Referências}

Fearnside, P. M. 2005. Brazil's Samuel Dam: lessons for hydroelectric development policy and the environment in Amazonia. Environmental Management 35, n 1: 1-19. https://doi.org/10.1007/s00267-004-0100-3.

Moran, Emilio F. 2016. Roads and dams: infrastructure-driven transformations in the Brazilian Amazon. Ambiente e Sociedade 19, $\mathrm{n}^{\circ}$ 2: 205-218. https://doi. org/10.1590/1809-4422ASOC256V1922016.

Schultes, R. 1990. The healing forest: medicinal and toxic plants of Northwest Amazonia. Portland: OR-Dioscorides Press.

Schultes, R. 1979. Plants of the Gods: origins of hallucinogenic use. New York: McGraw-Hill.

Vainer, Carlos Bernardo. 2008. Conceito de "atingido": uma revisão do debate. Em Vidas alagadas: conflitos socioambientais, licenciamento e barragens, organizado por Franklin Daniel Rothman, 39-63. Viçosa: Ed. UFV.

\section{Agradecimentos}

Os autores Emilio Moran, Márcia Grisotti, Vanessa Boanada Fuchs, Maira Borges Fainguelernt e Assis da Costa Oliveira agradecem pelo suporte financeiro recebido da Fapesp (processo 2012/51465-0), NSF (processo 1639115), CNPq (processo 483030/2013-9), Capes e Conselho Nacional dos Direitos da Criança e do Adolescente (Termo de Cooperação Técnica n. 001/2016).

\section{Márcia Grisotti}

Professora associada do departamento de Sociologia e Ciência Política da Universidade Federal de Santa Catarina (Ufsc, Florianópolis, SC, Brasil). Coordenadora do Núcleo de Pesquisa Ecos - Ecologia Humana e Sociologia da Saúde.

\section{Emilio Federico Moran}

John A. Hannah Distinguished Professor, Center for Global Change and Earth Observations and Dept. of Geography, Michigan State University (MSU), East Lansing, MI, USA. 